\title{
Prevalence of Viral Coinfections with EBV and CMV and Its Correlation with CD4 Count In HIV-1 Serpositive Patients
}

\section{Deepali Patekar ${ }^{1}$, Supriya Kheur ${ }^{2 *}$, Pravin More ${ }^{1}$, Chaitrali Hambire ${ }^{3}$ and Mohit Kheur ${ }^{4}$}

${ }^{1}$ Department of Oral Pathology, Saraswati-Dhanwantari Dental College \& Hospital and Post Graduate Research Institute, Dr. Prafulla Patil Educational \& Hospital Campus, Parbhani, India

${ }^{2}$ Department of Oral Pathology, Dr. D.Y.Patil Dental College \& Hospital, DPU, Pimpri, Pune, India

${ }^{3}$ Department of Pedodontics, SMBT Dental College, Sangamner, Maharashtra, India

${ }^{4}$ Department of Prosthodontia, M.A.Rangoonwala College of Dental Sciences, Camp, Pune, India

\begin{abstract}
Objectives: The objective of this study is to estimate the level of antibodies to EBV and Human Cytomegalovirus (HCMV) in peripheral blood in seropositive HIV-1 patients and its correlation with $\mathrm{CD}_{4}$ cell count and clinical and demographical details.

Materials and Methods: 60 patients who are HIV-1 seropositive were included in the study, with 30 seronegative patients as control group. After proper written consent, thorough oral examination was done and CD4 cell count of the patient was noted. Serological assessment of antibodies against EBV \& CMV was done as an indicator for viral coinfection in these patients.

Results: There was a significant increase in the antibody titer against EBV \& CMV in the patients with CD4 count less than 200 as compared to HIV-1 seropositive patients with CD4 count more than 200 . The oral manifestations were seen more prominently in direct correlation with CD4 count of the patients.

Conclusion: There was a higher titre of EBV-1 and CMV antibodies in HIV-1 seropositive patients. A correlation between antibodies to CMV and CD4 count is seen in our population, with $86.4 \%$ of patients presenting with oral manifestations.
\end{abstract}

\section{Keywords: Oral Manifestations; CD4 count; EBV; CMV; HIV-1}

\section{Introduction}

Human immunodeficiency virus (HIV) causes devastation to the body by attacking the host's immune system. In a healthy individual, there exists a delicate balance between the complex microbial ecology of the mouth and body's immune system [1]. When this retrovirus enters human host cells, it destroys this delicate balance thereby rendering the host susceptible to a lot of life threatening opportunistic infections, neurological disorders, and unusual malignancies. The oral lesions found in HIV can be fungal, viral like CMV induced diseases and bacterial in origin [1]. The most common lesions of the oral mucosa, associated with HIV, according to Greenspan and Greenspan, are candidiasis, hairy leukoplakia, herpetic gingivostomatitis, aphthous ulceration, necrotizing gingivitis, pigmented macules, Kaposi's sarcoma and periodontal diseases [1].

Amongst the various opportunistic infections, the issue of viral co infection among HIV / acquired immunodeficiency syndrome (AIDS) patients represents a growing public health concern worldwide. Viral co infections among an HIV-infected individual may affect the disease progression of HIV/AIDS and may accelerate the progression of these other viral infections to more severe illness due to HIV co-infection. Among the list of viruses that are likely to be co-infected with HIV, hepatitis $B$ virus (HBV), hepatitis C virus (HCV), herpes simplex virus including type 1 (HSV-1) and type 2 (HSV-2), and the Epstein-Bar virus (EBV) are the most important co infections among HIV/AIDS patients due to their pathogenicity and relatively high prevalence in populations affected by HIV [2]. It is suggested that, EBV may cause 1) gene transactivations; 2) abnormal serological response may precede HIV seroconversion and are frequently seen during HIV infection and a defective mechanism of immune surveillance of EBV is seen in the course of HIV infection. EBV is the causative agent of nonHodgkin's lymphoma (NHL) which is an AIDS-defining malignancy
[3]. Unlike Kaposi's sarcoma, the incidence of non-Hodgkin's lymphomas has not changed since the introduction of HAART [4]. The human cytomegalovirus (CMV) is a DNA-virus that belongs to the $\beta$-herpesviruses (HHV-5) group. CMV infection occurs frequently worldwide and CMV seroprevalence is estimated to range between $60 \%$ to above $90 \%$ in developed countries, with even higher rates (>90\%) in developing countries. The frequency of CMV infection in HIV-infected patients is high and there is compelling evidence for a significant role for CMV in HIV-disease progression [5,6]. There are few studies where comparison between blood and saliva has been done to detect antibodies against EBV and CMV in HIV patients. These studies has emphasized that saliva provides clues to local and systemic conditions [7-10]. We hypothesize that multiple pathogenic viral coinfections may negatively impact HIV-infected individuals.

\section{Null Hypothesis}

The level of antibodies against HCMV, and EBV in blood of HIV/ AIDS patients are not associated with CD4 cell counts and other clinical parameters like oral manifestations, age, sex as well as other demographic and behavioral factors $[7,11]$.

*Corresponding author: Supriya kheur, Professor and Head, Department of Ora Pathology, Dr. D.Y.Patil Dental College \& Hospital, DPU, Pimpri, Pune, India, Tel: +9-1-20-27659590; E-mail: supriya.kheur@dpu.edu.in

Received July 14, 2015; Accepted Novmeber 09, 2015; Published November 16 2015

Citation: Patekar D, Kheur S, More P, Hambire C, Kheur M (2015) Prevalence of Viral Coinfections with EBV and CMV and Its Correlation with CD4 Count In HIV 1 Serpositive Patients. J AIDS Clin Res 6: 520. doi:10.4172/2155-6113.1000520

Copyright: ( 2015 Patekar D, et al. This is an open-access article distributed under the terms of the Creative Commons Attribution License, which permits unrestricted use, distribution, and reproduction in any medium, provided the original author and source are credited. 
The present study was approved by the institutional ethics committee of the Dr D Y Patil Vidyapeeth, and Yashwantrao Chavan Hospital, - a referral centre for patients of HIV, and ART centre, at Pimpri, Maharashtra, India. A total of 60 known HIV seropositive patients were selected, and blood sample was drawn from the patients for CD4 count estimation, after obtaining written informed consent.

\section{Subject selection}

The patients visiting HIV referral centre OPD of Dr. D.Y.Patil Dental College and Hospital, Pimpri, Pune.All the patients were subjected to CD4 count, and for the purpose of comparison, two groups of HIV positive patients were formed and comparison with control group was made:

Group 1 - Thirty ( $\mathrm{n}=30)$ HIV seropositive patients with CD4 count less than $200(>200)$

Group 2 -Thirty $(n=30)$ HIV seropositive patients with CD4 count more than $200(<200)$

Group 3 - Thirty $(\mathrm{n}=30)$ HIV seronegative individuals.

Written consent was obtained from all the patients and their complete and relevant demographic information including age, sex, ethnicity, residential history, education status, sexual behaviour, drug abuse, and other risk factors were recorded. A medical history was obtained for each patient, and all patients received a full clinical examination \& oral examination. The diagnosis of the viral opportunistic infections was based exclusively on well defined clinical symptoms and the determination of specific antibodies in serum by ELISA. Inclusion criteria mainly included all patients above 18 years and willing to participate in the study. Patients with systemic complications and pregnant and lactating mothers were excluded from the study.

\section{Collection of blood sample}

After informed consent (Annexure No) from the patient and under all aseptic precautions, about $5 \mathrm{ml}$ venous blood was collected from antecubital vein of each individual into plain sterile bulb. The sample was then allowed to clot at room temperature for about 2 hours and was then centrifuged at $3000 \mathrm{rpm}$ for 10 minutes, to separate the serum. Immediately this serum was stored at $-20^{\circ} \mathrm{C}$ until further laboratory test. The ELISA test of present study was conducted in the National AIDS Research Institute (NARI).

Serum IgG Titres against EBV- The ELISA test was done collectively for all the samples. ELISA kit was used having reference number E0300, which is specifically used to detect quantitative levels of IgG antibody to EBV in human serum.

Serum IgG Titers against CMV- The ELISA test was done collectively for all the samples. ELISA kit was used having reference number CM027G, which is specifically used to detect quantitative levels of IgG antibodies to CMV in human serum.

\section{Results}

The study group comprised of total 90 individuals with equal sex distribution, with mean age being $36 \pm 16$ years. The patients included in the study were age and sex matched, residing in different regions of Maharashtra.

In the present study all the 3 groups comprised of 30 samples each. The study group of HIV -seropositive patients was divided further on basis of their CD 4 counts. The results of the present study were statistically analyzed using SPSS 11.5 version, ANOVA and Chi-square test.

The study showed statistically significant increase in co infection with EBV-1 ( Table 1) and CMV (Table 2) in between the groups with patients having CD4 count less than 200( Group 1) having greatest titre of antibodies as compared to other two groups. The analysis of intergroup variability between the titres of EBV-1 and CMV is also statistically significant (Table 3 ).

Oral manifestations were significantly more seen in Group 1 as compared to other study and control groups (Table 4). The most common oral manifestation seen in our group of patients was non specific gingivitis and periodontitis.

Group 1: Candidiasis (C)-10.0\%,Angular Cheilitis ( AC)-20.3\%; Periodontitis (P)-20.3\%; Glossitis (G)-10.3\%; Ucler ( U)-16.3\%

Group 2: C-3.3\%; AC-0\%; P-20.6\%; G-20.0\%; U-0\%

\section{Discussion}

The newer approaches to the treatment and management of HIV-1 seropositive patients have opened more avenues to prolong the life span of these patients. Hence, in many aspects AIDS is now compared with a chronic illness, which if managed properly can lead to decreased morbidity. One of the distressing aspects of HIV illness are the opportunistic infections, mainly viral infections. Quesnel et al. studied the progression of the HIV-1 infection with the help of CD 4 cell number in the blood. They found that the titres of IgG antibodies to Viral Capsid Antigen were significantly higher in HIV seropositive compared to seronegative subjects and increased significantly when CD4 cell number decreased $[4,8,9]$. In order to estimate the specific antibody responses directed to Epstein-Barr virus (EBV) and cytomegalovirus

\begin{tabular}{|c|c|c|c|c|c|}
\hline \multirow{2}{*}{ Group } & \multirow[t]{2}{*}{$\mathrm{n}$} & \multicolumn{2}{|c|}{ CMV } & \multirow{2}{*}{ F Value } & \multirow{2}{*}{ P Value } \\
\hline & & Mean & SD & & \\
\hline Group I (CD4<200) & 30 & 1.97 & 0.46 & \multirow{3}{*}{21.31} & \multirow{3}{*}{$<0.0001$} \\
\hline Group II (CD4>200) & 30 & 1.39 & 0.41 & & \\
\hline Group III (CD4<200) & 30 & 1.32 & 0.41 & & \\
\hline
\end{tabular}

By applying post hoc Tukey's test

Group I Vs Group II: P = 0.000, Group I Vs Group III: 0.000

Table 1: Comparison of CMV in study groups.

\begin{tabular}{|c|c|c|c|c|c|}
\hline \multirow{2}{*}{ Group } & \multirow[t]{2}{*}{$\mathrm{n}$} & \multicolumn{2}{|c|}{ EBV } & \multirow{2}{*}{ F Value } & \multirow{2}{*}{ P Value } \\
\hline & & Mean & SD & & \\
\hline Group I (CD4<200) & 30 & 2.96 & 0.49 & \multirow{3}{*}{13.85} & \multirow{3}{*}{$<0.0001$} \\
\hline Group II (CD4>200) & 30 & 2.82 & 0.65 & & \\
\hline Group III (CD4<200) & 30 & 2.13 & 0.79 & & \\
\hline
\end{tabular}

By applying post hoc Tukey's test

Group I Vs Group III: P=0.000, Group II Vs Group III: 0.000

Table 2: Comparison of EBV in study groups.

\begin{tabular}{|l|c|c|c|c|c|c|}
\hline \multirow{2}{*}{ Parameters } & \multicolumn{2}{|c|}{ CMV } & \multicolumn{2}{c|}{ EBV } & \multirow{2}{*}{ Z Value } & \multirow{2}{*}{ P Value } \\
\cline { 2 - 7 } & Mean & SD & Mean & SD & & \\
\hline Gr. I(Cd4<200) & 1.97 & 0.46 & 2.96 & 0.49 & 8.07 & $<0.0001$ \\
\hline Gr. II(Cd4>200) & 1.39 & 0.41 & 2.82 & 0.65 & 10.19 & $<0.0001$ \\
\hline Gr. III(Control) & 1.32 & 0.41 & 2.13 & 0.79 & 4.98 & $<0.0001$ \\
\hline
\end{tabular}

Table 3: Comparison of CMV and EBV in study groups.

\begin{tabular}{|c|c|c|c|c|}
\hline \multirow{2}{*}{ Parameter } & Gr. I (CD 4<200) & Gr. II (CD 4>200) & Z Value & P Value \\
\cline { 2 - 5 } & $\mathrm{n}=30$ & $\mathrm{n}=30$ & & \\
\hline Oral manifestation & $26(86.67)$ & $15(50)$ & 3.32 & $<0.005$ \\
\hline
\end{tabular}

Table 4: Comparison of oral manifestation in group I and group II. 
$(\mathrm{CMV})$ and to provide serological evidence suggesting reactivation of these viruses able to accelerate the immunodeficiency, we studied IgG titres to EBV and CMV in the serum of HIV positive patients in relation to the CD4 cell number. Thus the purpose of present study was to compare antibodies against EBV and CMV in peripheral blood in HIV seropositive individuals and HIV seronegative individuals. An attempt was made to correlate oral manifestations among HIV seropositive study group with CD4 count and antibodies titre.

The present study comprised of 3 groups, Group 1 (HIV negative subjects with mean age of $36.50+/-6.9$; Group 2 (HIV seropositive patients with CD4 less than 200; with mean age of $38.50+/-8.8$ years and Group 3 (HIV seropositive patients with CD4 more then 200 with mean age of 33. I $6+/-9.0$ In this study of $60 \mathrm{HIV}$ positive patients, the mean CD4 count was 284.61 cells $/ \mathrm{mm}^{3}$. The CD4 count in present study ranged between 7 to 1056 cells $/ \mathrm{mm}^{3}$. The normal CD4 count ranges between $430-1300$ cells $/ \mathrm{mm}^{3}$ in healthy persons. The present study did reveal a significant correlation between age of patient and $\mathrm{CD} 4+$ cell count correlation whereas there were no significant comparable difference seen with individual gender and CD4 count. Oral lesions play an important role in the clinical management of HIV/ AIDS patients $[1,8,10]$. Oral manifestations are important in early diagnosis as well as in monitoring the progress of the disease. In our study, it was evident that there was high number of HIV-1 seropositive patients $(86.6 \%)$ with oral manifestations seen more in CD4 <200 (L group) as compared to $\mathrm{M}$ group where there was only $50 \%$ patients had oral manifestations.

Hence, as the CD4 count decreased below 200 there was an increase in candidiasis and angular cheilitis. We found no alteration in the percentage of patients suffering from HIV- periodontitis and gingivitis with CD4 count. Langford et al. [9] found oral lesions such as ulcerations of oral cavity associated with CMV. The oral ulcers were seen on lip, gingiva, buccal mucosa \& tongue. According to their suggestion, ulcers may be caused due to CMV-HIV co infection due to marked decrease in CD4 cell count which may initiate immunologic \& inflammatory reactions. In our study non-specific ulcer were seen mostly on lower lip making it evidently a major factor to be considered. Greenspan et al. [11] Laskaris et al. [12], Kololotronis et al. [13] in their study observed oral candidiasis \& OHL were the most common oral lesions.

Considering Indian studies, Anil et al., Ranganathan and Reddy, Hazarey et al. in their studies found correlation between CD4 count below 200 cells $/ \mathrm{mm}^{3}$ and oral candidiasis as significant. These results are consistent with our study also. The statistical analysis in our study showed that the mean CD4 count of the patients with oral manifestations 207 cells $/ \mathrm{mm}^{3}$ was less than patients without oral manifestations (291cells $\left./ \mathrm{mm}^{3}\right)$. This difference was found to be statistically significant $(\mathrm{P}=0.002$, $\mathrm{t}$-test). From the above findings, it can be inferred that oral manifestations have a definite association with reduced CD4 count in HIV patients.

In present study estimation of progression of HIV infection was done with the help of CD4 T-cell count in the blood. The titres of IgG antibodies VCA is significantly higher in HIV seropositive compare to seronegative subjects \& increased significantly when CD4 T-cell count decreased. In our study we found mean EBV antibodies higher than mean CMV antibodies with p-value being $<0.001$ which is highly significant. EBV antibodies level with $\mathrm{CD} 4 \mathrm{~T}$-cell count correlation did not show statistical significant difference in Group 1 and 2 but statistically significant difference in antibodies level against CMV was present between groups. Thus, CMV proliferation is probably associated with decreasing CD4 count thereby deteriorating condition. Sachithanandan et al. in their study on detection of opportunistic DNA viral infection among HIV individual reported that early diagnosis of opportunistic viruses will be able to reduce the risk of disease progression [14]. They found among the 68 HIV 1 infective individual $72 \%$ were positive for EBV, $7 \%$ were positive for CMV \& all CMV Positive patients had CD4+T cells count of less than 200 cells/ $\mu \mathrm{L}$. They stated though EBV the most prevalent opportunistic viral infection among HIV infected individuals there was no significant association between EBV load CD4+ T cells count \& HIV-1 virus load which is similar to our study.

The present study shows the prevalence of IgG antibodies to EBV and CMV was significantly higher in HIV seropositive study group as compared to seronegative control group. The titres for CMV vary significantly with $\mathrm{CD} 4$ cell but the titres for EBV did not vary significantly when CD4 cell number declined. The demonstration of increased titres of antibodies to EBV and increased prevalence of CMV in HIV positive subjects with normal CD4 cell number compared to high risk HIV negative subjects suggests a very early reactivation of these viruses during the course of HIV infections. The increase of VCA IgG titres in relation to the decrease of CD4 cell number provides serological evidence for the high frequency of active EBV infection in the late stage of HIV disease as also confirmed by the presence of numerous EBV particles in blood and secretions of immunocompromised HIV seropositive patients [15-17].

\section{Conclusion}

The present study showed a higher incidence of EBV-1 and CMV antibodies in HIV-1 seropositive patients and it was directly correlated with the CD4 count .A correlation between antibodies to CMV and CD4 count is seen in our population, with $86.4 \%$ of patients presenting with oral manifestations.

Thus this study was undertaken with an aim of providing baseline data on viral opportunistic infections in HIV seropositive population as part of the preliminary investigation on the dynamics of viral opportunistic infections in immune compromised population of India. Further investigations have to be undertaken with matched control samples as case control analysis with respect to EBV-1, EBV-2, HCMV infection in HIV seropositive individuals.

\section{References}

1. Adurogbangba MI, Aderinokun GA, Odaibo GN, Olaleye OD, Lawoyin TO (2004) Oro-facial lesions and CD4 counts associated with HIVIAIDS in an adult population in Oyo State, Nigeria. Oral Dis 10: 319-326.

2. He N, Chen L, Lin HJ, Zhang M, Wei J, et al. (2011) Multiple viral coinfections among HIVIAIDS patients in China. Biosci Trends 5: 1-9.

3. Telenti A, Uehlinger DE, Marchesi F, Germann D, Malinverni R, et al. (1993) Epstein-Barr virus infection in HIV-positive patients. Eur J Clin Microbiol Infect Dis 12: 601-609.

4. Epstein JB (2007) Oral malignancies associated with HIV. J Can Dent Assoc 73: 953-956.

5. Olson D, Reinhold E, Schmidt, Benjamin A, Bollmann (2012) Treatment and Prevention of Cytomegalovirus-Associated Disease in HIV-1 Infection in the Era of HAART. HIV Therapy 4: 413-436.

6. Krishna B, Ashalatha G, Baghirath V, Rajani Kanth AV, Malathi N (2010) Saliva as a diagnostic bio fluid. J Oro fac Sci 2: 30-34.

7. Chakraborty N, Bhattacharyya S, De C, Mukherjee A, Bhattacharya D, et al (2010) Incidence of multiple Herpesvirus infection in HIV seropositive patients a big concern for Eastern Indian scenario. Virol J 7: 147.

8. Quesnel A, Pozzetto B, Touraine F, Moja P, Lucht F, et al. (1992) Antibodies 
Citation: Patekar D, Kheur S, More P, Hambire C, Kheur M (2015) Prevalence of Viral Coinfections with EBV and CMV and Its Correlation with CD4 Count In HIV-1 Serpositive Patients. J AIDS Clin Res 6: 520. doi:10.4172/2155-6113.1000520

to Epstein-Barr virus and cytomegalovirus in relation to CD4 cell number in human immunodeficiency virus 1 infection. J Med Virol 36: 60-64.

9. Langford A, Kunze R, Timm H, Ruf B, Reichart P (1990) Cytomegalovirus associated oral ulcerations in HIV-infected patients. J Oral Pathol Med 19 71-76.

10. Khongkunthian P, Grote M, Isaratanan W, Plyaworawong S, Reichart PA (2001) Oral manifestations in HIV-positive adults from Northern Thailand. J Oral Pathol Med 30: 220-223.

11. Greenspan JS (1997) Sentinels and signposts: the epidemiology and significance of the oral manifestations of HIV disease. Oral Dis 3 Suppl 1: S13-17.

12. Laskaris G, Hadjivassiliou M, Stratigos J (1992) Oral signs and symptoms in 160 Greek HIV-infected patients. J Oral Pathol Med 21: 120-123.
13. Kolokotronis A, Kioses V, Antoniades D, Mandraveli K, Doutsos I, et al. (1994) Immunologic status in patients infected with HIV with oral candidiasis and hairy leukoplakia. Oral Surg Oral Med Oral Pathol 78: 41-46.

14. Sachithanandham J, Ramamurthy M, Kannangai R, Daniel HD, Abraham OC et al. (2009) Detection of opportunistic DNA viral infections by multiplex PCR among HIV infected individuals receiving care at a tertiary care hospital in South India. Indian J Med Microbiol 27: 210-216.

15. Sontakke SA, Umarji HR, Karjodkar F (2011) Comparison of oral manifestations with CD4 count in HIV-infected patients. Indian J Dent Res 22: 732.

16. Sixbey JW, Shirley P, Chesney PJ, Buntin DM, Resnick L (1989) Detection of a second widespread strain of Epstein-Barr virus. Lancet 2: 761-765.

17. Sculley TB, Cross SM, Borrow P, Cooper DA (1988) Prevalence of antibodies to Epstein-Barr virus nuclear antigen $2 \mathrm{~B}$ in persons infected with the human immunodeficiency virus. J Infect Dis 158: 186-192. 